\title{
Innovative Controller Design for a 5MW Wind Turbine Blade
}

\author{
Ranjeet Agarwala ${ }^{1} \&$ Robert A. Chin ${ }^{1}$ \\ 1 Department of Technology Systems, College of Engineering and Technology, East Carolina University, \\ Greenville, NC, USA-27858 \\ Correspondence: Ranjeet Agarwala, Department of Technology Systems, College of Engineering and \\ Technology, East Carolina University, Greenville, NC, USA-27858. Tel: 1-252-328-9642. E-mail: \\ agarwalar@ecu.edu
}

Received: March 30, 2018

Accepted: May 31, $2018 \quad$ Online Published: July 29, 2018

doi:10.5539/jsd.v11n4p78

URL: https://doi.org/10.5539/jsd.v11n4p78

\begin{abstract}
The development and evaluation of a nonlinear pitch controller for wind turbine blades and the design and modeling of an associated actuator and controller was examined. The pitch actuator and controller were modeled and analyzed using Pneumatically Actuated Muscles (PAMs) for actively pitching the wind turbine blade. PAMs are very light and have a high specific work and a good contraction ratio. Proportional Integral and Derivative (PID) controllers were envisaged for the wind turbine pitching system at the blade tip due to its routine usage in the wind turbine industry. Deployment of controllers enables effective pitch angle tracking for power abatement at various configurations. The controller was subjected to four pitch angle trajectory signals. PID controllers were tuned to achieve satisfactory performance when subjected to the test signal. Low pitch angle errors resulted in satisfactory blade pitch angle tracking. Deployment of these controllers enhances wind turbine performance and reliability. The data suggest that the pitch system and actuator that was modeled using PAMs and PID controllers is effective providing robust pitch angle trajectory tracking. The results suggest that the proposed design can be successfully integrated into the family of wind turbine blade pitch angle controller technologies.
\end{abstract}

Keywords: renewable energy, wind energy, wind turbine, wind turbine control

\section{Introduction}

\subsection{Problem Introduction}

Wind turbines are primarily controlled by varying the pitch angle of the blade at their roots where the blades are attached to the hub of the rotor. Minute deviations in pitch angle due to wind variations can lead to significant fluctuations in turbine blade loads affecting rated turbine power output, stability, and turbine life. Actuations of pitch angle are inhibited by high blade inertia leading to slower control response time at high or fluctuating speeds. Power required for full length pitching for large blades are high thereby undermining power generation. Mechanisms for full length pitching are large, complex, and expensive requiring higher manufacturing and maintenance costs.

\subsection{Wind Turbine Blade Theory}

For a section of blade - see Figure 1, the lift force and moment (Singh \& Yim, 2003; Fung, 2002; Hoogedoorn, Jacobs, \& Beyene, 2010) are given in Equations (1) and (2). The lift force of any blade section results in a pressure difference between the upper and lower surface of the airfoil when the air flows past it. The pressure difference is caused due to the geometry and the camber of the airfoil which causes changing velocities at the top and bottom surface of the airfoil. The pressure difference when multiplied by the area of a section of the blade length produces the lift force of $d L$. 


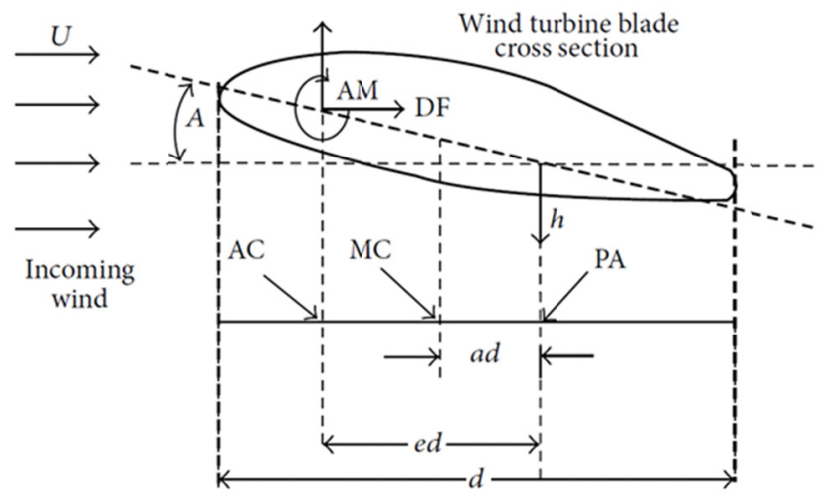

Figure 1. Cross-section of a wind turbine blade. 2D quasi-steady aerodynamic equations of an airfoil and the SePCaT are based on parameters as depicted here

The lift coefficient is a non-dimensional term based on the geometry of the airfoil impacted by lift forces. Similarly, the aerodynamic moment is calculated by multiplying the vertical forces with the chord length. The moment coefficient is a non-dimensional term that captures the geometry of the airfoil impacted by aero-dynamic moment.

$$
\begin{aligned}
& d L=\frac{1}{2} \rho U^{2} d C L_{A} d l+\frac{1}{2} \rho U^{2} d_{P B} C L_{P B_{C A}} d l_{P B} \\
& d M=\frac{1}{2} \rho U^{2} d^{2} C M_{A} d l+\frac{1}{2} \rho U^{2} d_{P B}{ }^{2} C M_{P B_{C A}} d l_{P B}
\end{aligned}
$$

$U$ is wind velocity in $\mathrm{m} / \mathrm{s}, d$ is the airfoil chord length for main blade in $\mathrm{m}, \mathrm{d} l$ is the incremental length of the blade for main blade in $\mathrm{m}, d l_{P B}$ is the incremental airfoil chord length for SePCaT in $\mathrm{m}, \rho$ is the density of air in $\mathrm{kg} / \mathrm{m}^{3}, C M_{A}$ is the moment coefficient per angle of attack, $C L_{A}$ is the lift coefficient per angle of attack, $C M P B_{C A}$ is the moment coefficient per partial blade control angle, $C L P B_{C A}$ is the lift coefficient per partial blade control angle. The total combined lift and moment for the main blade and SePCaT is obtained by integrating the lift and moment values for the entire blade length exposed to wind.

\subsection{Relevant Scholarship}

Many researchers have proposed alternate control strategies for wind turbines. Akram et al. (2017) conducted success aerodynamic load control using pitch actuation studies on vertical wind turbines. Chen and Qin (2017) used trailing edge controllers to control and actuate wind turbine blades and for load control. Gao and Gao (2016) used optimization and compensation control methods to control non-linear wind turbines. As wind turbines continue to grow and achieve power ratings up to $20 \mathrm{MW}$ (Steel, 2015) capacities, independent or collective full-length pitch control become increasingly cumbersome.

Some wind turbine control design includes telescopic blades, trailing edge- flaps, transitional tabs, plasma actuation, flow detectors, and active flaps to name a few. Daynes and Weaver (2012a) and Daynes and Weaver (2012b) studied a NACA63-418 blade section comprising a 20 percent chord length trailing edge-flap controller and found that the lift coefficient changed by a value of 1.0 when the flap angle was varied from -10 to 10 degrees.

Versailles et al. (2011) evaluated the efficacy of plasma actuation to control lift force of a wind turbine blade and observed a lift reduction of 30 to 50 percent.

Wilson and Robinett (2011) investigated trailing edge-flaps for controlling and reducing aerodynamic loads by 20-30 percent allowing energy optimization. These wind turbine studies were based on 2D analysis. 2D analysis does not consider the geometrical twist of the blade, the effect of varying airfoil sectional geometries, and the type of airfoil.

Agarwala and Ro (2013) focused on 3D aerodynamic analysis and control of a wind turbine blade via 3D control surface design and deployment of trailing edge mid and end-flaps. Although trailing edge-flaps, transitional tabs, plasma actuation, flow detectors, and active flaps offer excellent alternatives, nevertheless they add to rotor complexity, increase manufacturing, maintenance, and deployment costs. They also create discontinuities in the 
blade which lead to installation and actuation complexities.

Imraan et al. (2013) conceptualized telescopic wind turbine blades having chord ratios of 0.6 and studied the influence of blade extension on blade loads. Mechanism proposed by them allowed linear actuation of the blade length for load adaptation. Their methods although novel present complexities and increased manufacturing costs.

Agarwala and Ro $(2014,2015)$ proposed focused on the design, evaluation, and analysis of innovative rotor blades for large wind turbines through the formulation of a novel and simple separated pitch control strategy at blade tip (SePCaT) for a large MW wind turbine. SePCaT5 indicates 5\% of the total blade length while SePCaT30 indicates $30 \%$ of the total blade length. Deployment of SePCaT facilitated new innovative design whereby a larger portion of the blade was aerodynamically available while maintaining structural effectiveness thus streamlining blade geometric and structural characteristics. The entire blade along with the root was aerodynamically more effective when compared to the traditional design and contributes to the aerodynamic effectiveness for power extraction.

\subsection{Design Overview}

Due to the inherent structural nonlinearities of wind turbines (Singh \& Yim, 2003), it was paramount to design an effective nonlinear controller for controlling the pitching mechanism of the wind turbine blade. This study focused on the design of non-linear pitch control of wind turbine blades and the design and modeling of a non-linear actuator and associated controller. The pitch actuator and controller were modeled and analyzed using PAMs for actively pitching the blade. The goal of the actuator design was to keep them as light as possible while exhibiting strong actuator force. PID controllers were envisioned for the wind turbine pitching system at the blade tip. PID controllers were then incorporated to control the pitch angle due to its routine usage in the wind turbine industry.

A PAM (http://www.festo.com/cat/nl-bebe/data/doc engb/PDF/EN/DMSP-MAS EN.PDF) was envisioned to actuate the SePCaT (Woods, Kothera, \& Wereley, 2014; Woods, Kothera, Sirohi \& Wereley, 2011; Woods, Kothera, \& Wereley, 2011). The goal of the actuator design was to keep them as light as possible while exhibiting strong actuator force. PAMs are very light and have a high specific work and a good contraction ratio. PAMs are comprised of an inner elastomeric ring, outer braided sleeve, and two end fittings - see Figure 2.

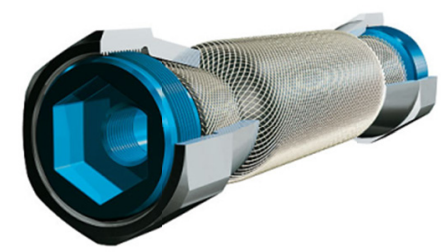

Figure 2. PAM operation. PAMs contract when the inner bladder expands when air pressure is applied. The braided sleeve expands radially. http://www.festo.com/cat/nl-bebe/data/doc engb/PDF/EN/DMSP-MAS EN.PDF

PAMs or clusters of PAMs were used to pitch the SePCaT during high winds in a wind tunnel. As depicted in Figures 3 and 4, PAM combinations 1 and 2, when actuated, allowed the SePCaT to be pitched to feather while PAMs

3 and 4, when actuated, allowed the SePCaT to be pitched to stall.

Here,

$L_{s}$ is the lift force;

$W$ is the weight of SePCaT;

$x_{m}$ is the distance of the aerodynamic center from the SePCaT pitching axis;

$x_{g}$ is the distance of the center of gravity from the SePCaT pitching axis;

$k_{P A M 1}$ and $k_{P A M 2}$ are PAM constants;

$\delta_{1}$ and $\delta_{2}$ are PAM deflections;

$d_{P A M 1}$ and $d_{P A M 2}$ are distances of the PAM line of action to the SePCaT pitching axis. 


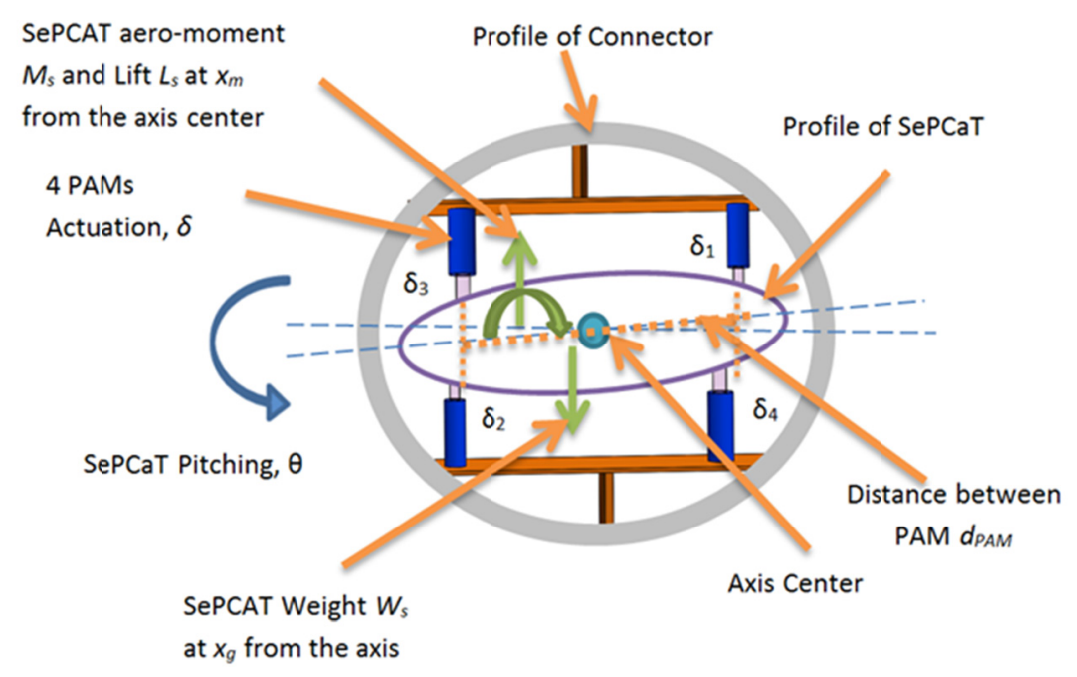

Figure 3. SePCaT actuation enabled (PAM). The setup depicts the side view of SePCaT

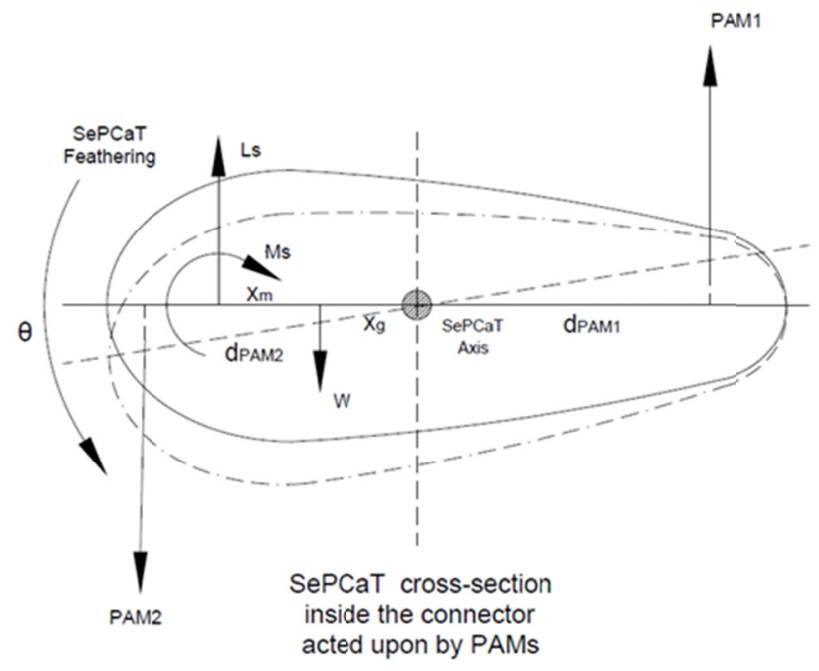

Figure 4. Concept of SePCaT actuation enabled by PAM

The equation for SePCaT derived from Lagrange's equations are given as follows (Woods, Kothera, \& Wereley, 2014; Woods, Kothera, Sirohi \& Wereley, 2011; Woods, Kothera, \& Wereley, 2011)

$$
\frac{d}{d t}\left(\frac{\partial L}{\partial \phi_{l}}\right)-\left(\frac{\partial L}{\partial q_{i}}\right)=Q_{i}
$$

Here the Lagrangian $L$ is given as a difference of SePCaT kinetic $T_{s}$ and potential energies $V_{s}$

$$
L=T_{s}-V_{s}
$$

The force $Q_{i}$ acting of the SePCaT is given as follows

$$
Q_{i}=Q_{\text {damping }}+Q_{\text {aero }}+Q_{\text {control }}
$$


The Lagrange kinteic energy of the SePCaT is given as

$$
T_{s}=\frac{1}{2} I_{s} \&
$$

The Lagrange potential energy of the $\mathrm{SePCaT}$ is given as

$$
V_{s}=\frac{1}{2} k_{\theta} \theta^{2}+\frac{1}{4} k_{\theta, N L} \theta^{4}
$$

The damping force is given as follows

$$
Q_{\text {damping }}=-\left(c_{\theta} \&+c_{\theta, N L} \operatorname{sign}(\&)\right)
$$

Therefore the equation of motion of SePCaT is given as

$$
I_{s} k_{\theta} \theta+k_{\theta, N L} \theta^{3}+\left(c_{\theta} \& 4 c_{\theta, N L} \operatorname{sign}(\&)\right)=Q_{\text {aero }}+Q_{\text {control }}
$$

$I_{s}$ is the moment of inertia of SePCaT, $c_{\theta}$ and $c_{\theta, N L}$ are linear and non-linear damping terms,and, $k_{\theta}$ and $k_{\theta, N L}$ are linear and non-linear spring stifness terms. $Q_{\text {aero }}$ is the change in aerodynamic moment and $Q_{\text {control }}$ is the controller moment applied. PAM actuator force is expressed in terms of the overall PAM actuator force $F$, Deflection $\delta$, and PAM constant

$k_{P A M}$. Both PAMs are treated having same geometrical and dynamical properties.

$F=k_{P A M} \delta$

$Q_{\text {aero }}$ and $Q_{\text {control }}$ are related as follows. Here $d_{P A M}$ is the distance of the PAM line of action to the SePCaT pitching axis and $\Delta \delta$ is the change in PAM displacement.

$2 k_{P A M} \Delta \delta d_{P A M}-Q_{\text {aero }}=Q_{\text {control }}$

Thererfore Equation (10-11) becomes

$$
I_{s} k_{\theta} \theta+k_{\theta, N L} \theta^{3}+\left(c_{\theta} \&+c_{\theta, N L} \operatorname{sign}(\Leftrightarrow)\right)=2 k_{P A M} \Delta \delta d_{P A M}
$$

Finally, expressing Equation (12) as functions of $\theta$, and contoller input $u$ and parameter $b$,

$$
\begin{gathered}
f(\theta)=\frac{c_{\theta} \&}{I_{s}}+\frac{c_{\theta, N L} \operatorname{sign}(\Theta)}{I_{s}}+\frac{k_{\theta} \theta}{I_{s}}+\frac{k_{\theta, N L} \theta^{3}}{I_{s}} \\
b u=\frac{2 k_{P A M} \Delta \delta d_{P A M}}{I_{s}}, b=\frac{2 k_{P A M} d_{P A M}}{I_{s}}, u=\Delta \delta=\delta_{u}
\end{gathered}
$$

\section{Method}

\subsection{Wind Turbine Blade Model}

The entire blade along with SePCaT was digitized using the 5MW National Renewable Energy Laboratory (NREL) (Jonkman, 2009) turbine specifications in three-dimension (3D) and analyzed using 3D computational fluid dynamics (CFD) routines. 


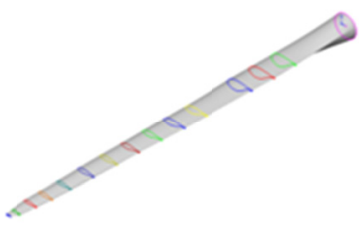

Figure 5(a). Full blade-3D view

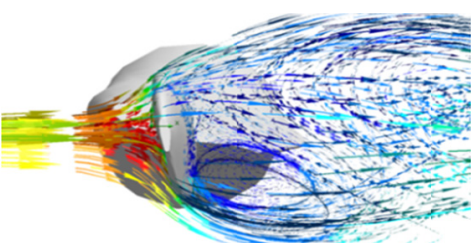

Figure 5(c). SePCaT

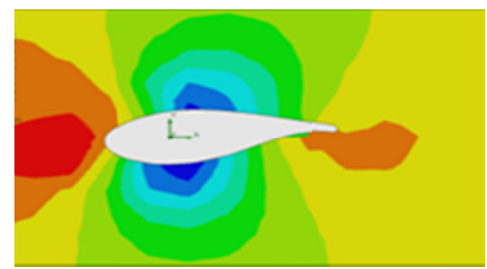

Figure 5 (b). CFD simulation

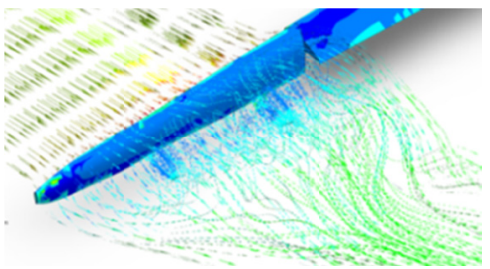

Figure 5(d). SePCaT pictorial view

Figure 5. SePCaT wind turbine configuration

The blade was first modeled as a standalone computer-aided design (CAD) model as shown in Figure 5(a) using Dassault Systèmes' SolidWorks. Airfoil shapes from various locations of the wind turbine blade were based on geometrical properties and co-ordinates of the model 5MW NREL wind turbine blade. Airfoil curves at various cross-sections were generated using Cartesian coordinate systems. Airfoils at each section were scaled and rotated by their chord lengths and values of angular twists. Various cross-sections were connected using inbuilt CAD modeling interpolation routines. Three-dimensional control surfaces are deployed as separated sections of partial blade length at the blade tip as depicted in Figure 5(a) through 5(d).

\subsection{Model Inputs}

The desired trajectory for SePCaT pitch angle in response to power abatement (shed excessive power to maintain $5 \mathrm{MW}$ ) in region 3 has been discussed in Agarwala and Ro (2014). SePCaT configurations, which varied from 5 to $30 \%$ of the blade length in $5 \%$ increments (SePCaT5, SePCaT10, SePCaT15, SePCaT20, SePCaT25, and SePCaT30), were evaluated by comparing them to aerodynamic responses of the traditional blade. As the wind speed increased by a factor of $1.1 \mathrm{U}(10 \%)$, the rotor power increased to around $6.75 \mathrm{MW}$ warranting a reduction to a factor of approximately .74. This was achieved by feathering SePCaT30 by 14, SePCaT25 by 16, SePCaT20 by 26 , and SePCaT15 by 30 degrees respectively. If wind speed increased by a factor of $1.2 \mathrm{U}(20 \%)$, the rotor power increased to around $8.33 \mathrm{MW}$ warranting a reduction to a factor of approximately .6 . This was achieved by feathering SePCaT30 by 18, SePCaT25 by 26 and SePCaT20 by 30 degrees respectively. As the wind speed increased by a factor of $1.3 \mathrm{U}(30 \%)$, the rotor power increased to around $11.75 \mathrm{MW}$ warranting a reduction to a factor of approximately .43. This was achieved by feathering SePCaT30 by 26 degrees. If wind speed increased by a factor of $1.4 \mathrm{U}(40 \%)$, the rotor power increased to around $14.30 \mathrm{MW}$ warranting a reduction to a factor of .35 approximately. This was achieved by feathering SePCaT30 by 32 degrees. The settings in Table 1 were used to build the desired SePCaT pitch angle trajectory for power shedding.

Table 1. SePCaT pitch angle trajectory setup values for desired pitch signals

\begin{tabular}{ccccccc}
\hline $\begin{array}{c}\text { Wind Speed } \\
\text { Factor }\end{array}$ & $\begin{array}{c}\text { Power } \\
\text { Produced }\end{array}$ & $\begin{array}{c}\text { Rated } \\
\text { Power }\end{array}$ & $\begin{array}{c}\text { SePCaT30 } \\
\text { Angle }\left(^{\circ}\right)\end{array}$ & $\begin{array}{c}\text { SePCaT25 } \\
\text { Angle }\left(^{\circ}\right)\end{array}$ & $\begin{array}{c}\text { SePCaT20 } \\
\text { Angle }\left(^{\circ}\right)\end{array}$ & $\begin{array}{c}\text { SePCaT15 } \\
\text { Angle }\left(^{\circ}\right)\end{array}$ \\
\hline 1.1 & $6.75 \mathrm{MW}$ & $5 \mathrm{MW}$ & 14 & 16 & 26 & 30 \\
1.2 & $8.33 \mathrm{MW}$ & $5 \mathrm{MW}$ & 18 & 26 & 30 & - \\
1.3 & $11.75 \mathrm{MW}$ & $5 \mathrm{MW}$ & 26 & - & - & - \\
1.4 & $14.30 \mathrm{MW}$ & $5 \mathrm{MW}$ & 32 & - & - & - \\
\hline
\end{tabular}

\section{Results}

Analysis focused on numerical investigation of the system and controller response to desired pitch angle trajectories based on Table 1. MATLAB and Simulink were used to study the response of the pitch dynamics as 
laid out in design overview in section1.3.

Initially the values were set to $\mathrm{P}=1, \mathrm{I}=1, \mathrm{D}=1$ for the unit step input and the response is observed as depicted in Figure 6. Figure 6 indicates the controller response when the values of are set to $\mathrm{P}=1, \mathrm{I}=1, \mathrm{D}=1$. The desired signal was plotted with a blue line and the response, with a red line. Examination of pitch error around the desired settling time as shown in Figure 7 indicates an error of .5 degrees. Subsequently, the values were set to $\mathrm{P}=1, \mathrm{I}=6, \mathrm{D}=1$ as depicted in Figure 8. The results of a pitch error of .25 degrees is shown in Figure 9.

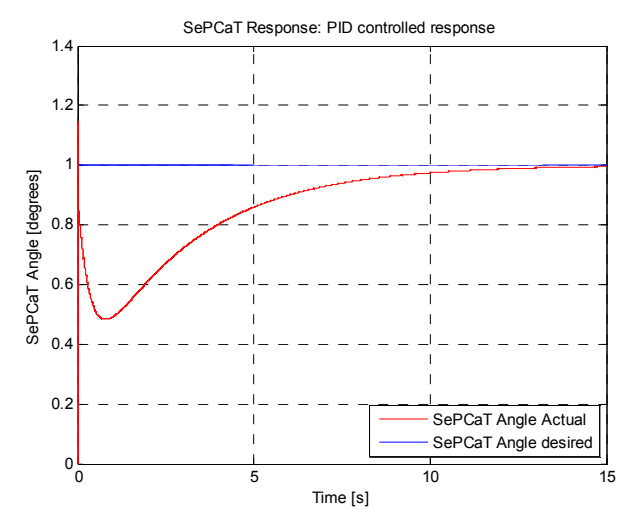

Figure 6. SePCaT response when PID is deployed. This response is for test signal

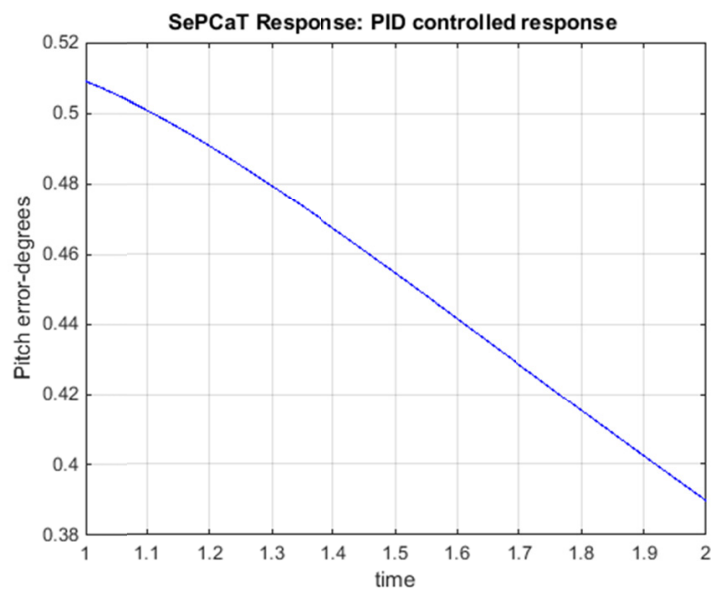

Figure 7. Pitch error when PID is deployed. This response is for test signal

Due to the unsatisfactory performance, optimum values of P, I, and D were sought to tune the system satisfactorily. The response is optimized by tuning the parameters until the settling time is around 1 second. The values are tuned to $\mathrm{P}=1.5, \mathrm{I}=18, \mathrm{D}=.15$ for the step input and the response is observed as depicted in Figure 10 . As shown in Figure 11, the pitch error was satisfactory at around .15 degrees. 


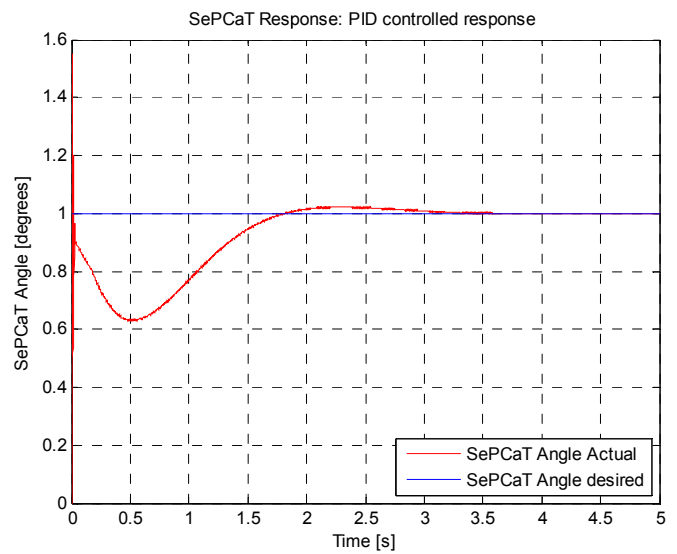

Figure 8. SePCaT response when PID is deployed. This response is for test signal

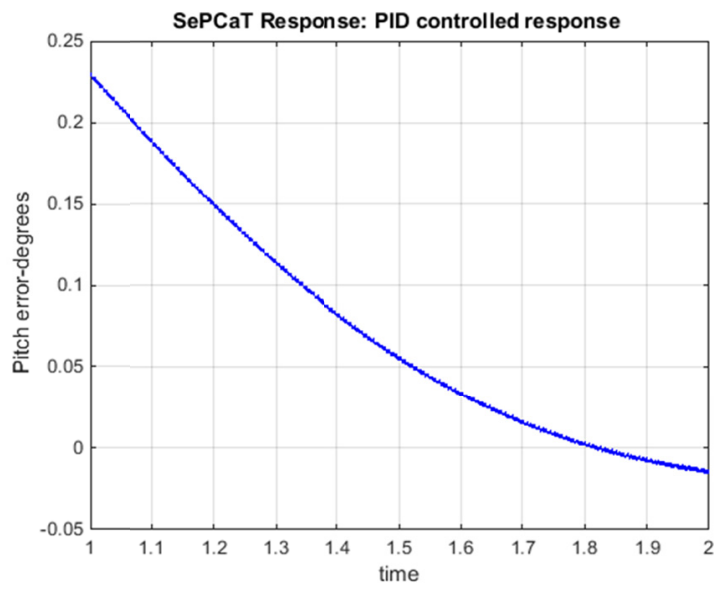

Figure 9. Pitch error when PID is deployed. This response is for test signal

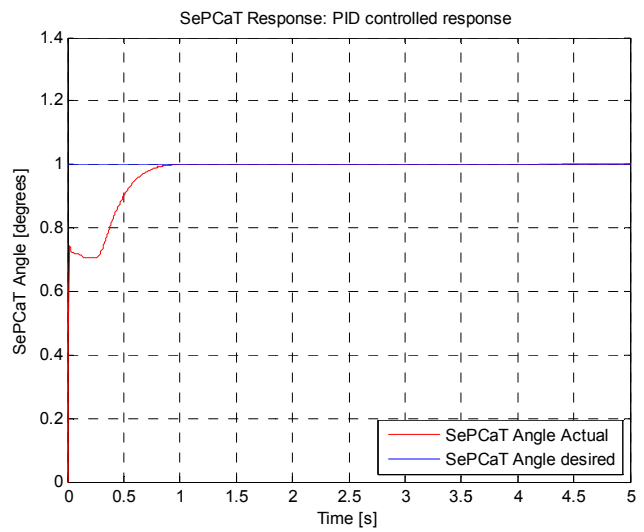

Figure 10. SePCaT response when PID is deployed. This response is for test signal 


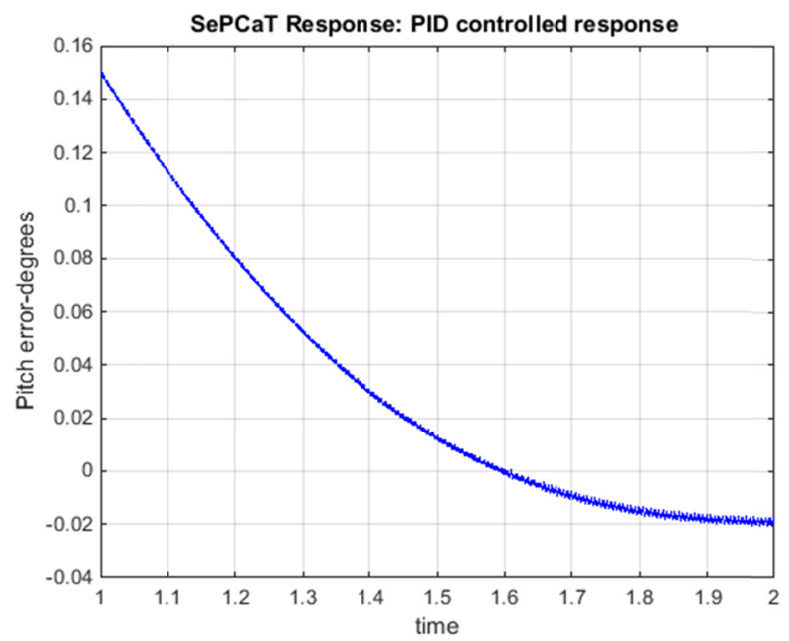

Figure 11. Pitch error when PID is deployed. This response is for test signal

The remaining signals were simulated and satisfactory tracking was achieved as shown in Figures 12, 13, and 14.

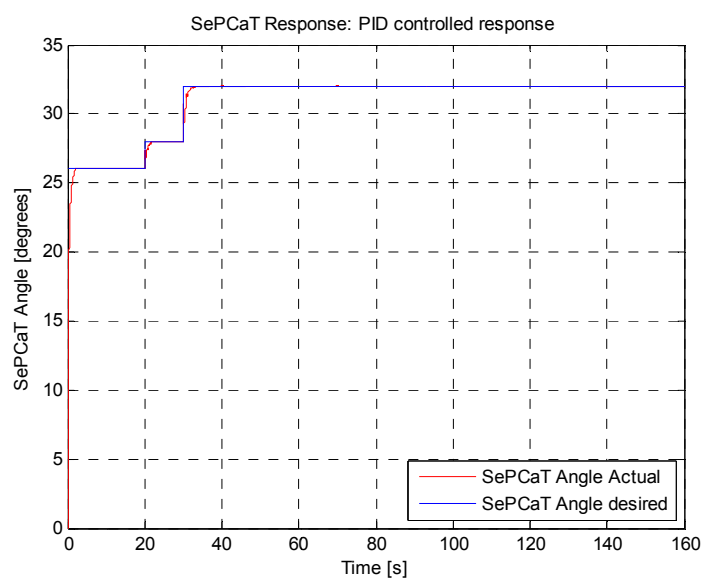

Figure 12. SePCaT response when PID is deployed. This response is for signal 1

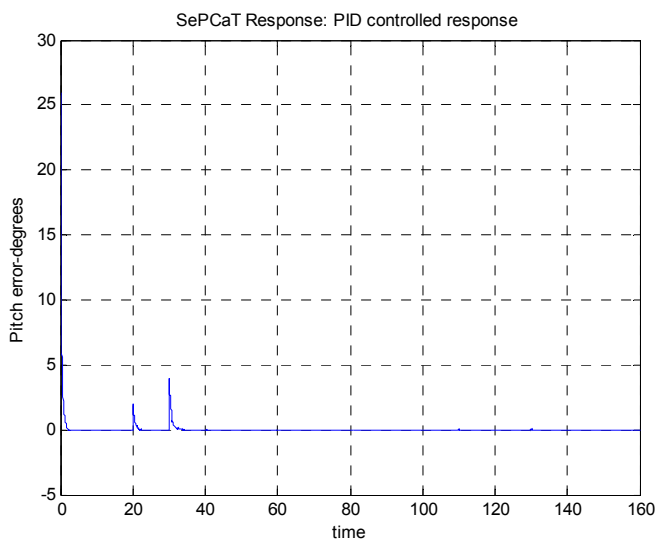

Figure 13. SePCaT pitch error when PID is deployed. This response is for signal 1 


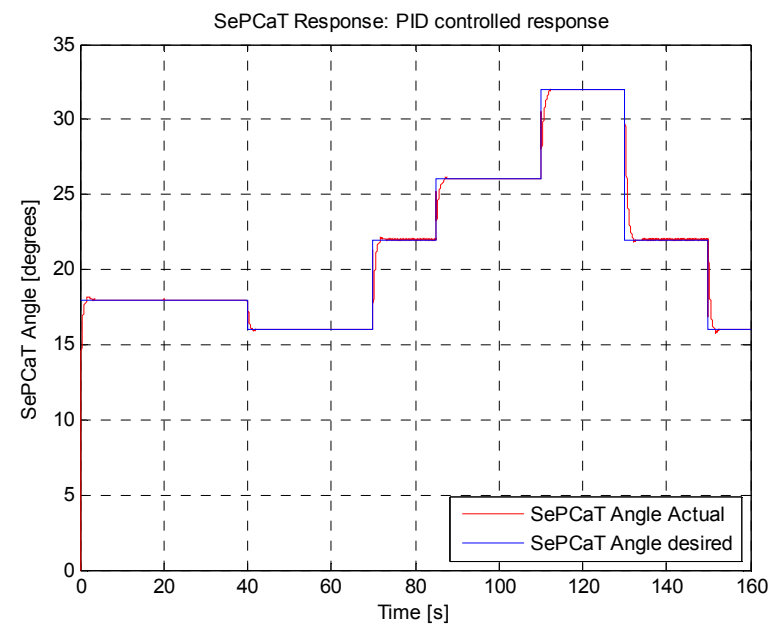

Figure 14. SePCaT response when PID is deployed. This response is for signal 2

Figure 12 indicates satisfactory controller tracking response to signal 2, and Figure 13 indicates the resulting error. The response indicates satisfactory tracking. However, sharp changes experienced during large step changes generated large errors during the start of the wind turbine signal change at 20 and 30 seconds. Figure 14 indicates satisfactory controller tracking response to signal 2.

\section{Conclusions}

This study focused on the development of an effective nonlinear pitch controller for wind turbine blades. The data suggest that the pitch system and actuator that was modeled using PAMs and PID controllers is effective in providing robust pitch angle trajectory tracking. The results suggest that the proposed design can be successfully integrated into the family of wind turbine blade pitch angle controller technologies.

The design and analysis of the pitch angle actuator and controller system provides effective tracking at various pitch angle trajectory settings. The model response and results suggest that the pitch controller design is robust and reliable. Initially the PID controllers were tuned to achieve satisfactory performance when subjected to the test signal. Pitch errors range from 0.5 degrees to .14 degrees for given test signals and PID values were selected for satisfactory tracking. For the remaining signals, tuned PID values were deployed and exhibited robust trajectory tracking. The controller and actuator design includes PAMs for actively pitching the blade thereby keeping the system light and exhibiting strong actuator force.

\section{References}

Agarwala, R. (2014). Separated Pitch Control at Tip (SePCaT): A Novel Blade Design and Associated Control Strategies for Large MW Wind Turbines (Doctoral dissertation, North Carolina State University, Raleigh, North Carolina, USA). Retrieved from http://www.lib.ncsu.edu/resolver/1840.16/9829

Agarwala, R., \& Ro, P. I. (2013). 3D analysis of lift and moment adaptation via control surface deployments on a 5 MW wind turbine blade. Wind Engineering, 37(5), 447-467. https://dx.doi.org/10.1260/0309-524X.37.5.447

Agarwala, R., \& Ro, P. I. (2015). Separated Pitch Control at Tip: Innovative Blade Design Explorations for Large MW Wind Turbine Blades. Journal of Wind Energy, 2015. Hindawi. https://dx.doi.org/10.1155/2015/895974

Akram, B., Branger, H., Paillard, B., Roy, S., Christopher, L., \& Bourras, D. (2017, September). Study of the aerodynamic properties of a wind VAWT turbine blade and evaluation of the effect of the pitch control. In 13th EAWE on Wind Energy.

Chen, H., \& Qin, N. (2017). Trailing-edge flow control for wind turbine performance and load control. Renewable Energy, 105, 419-435. https://dx.doi.org/10.1016/j.renene.2016.12.073

Daynes, S., \& Weaver, P. M. (2012a). A morphing trailing edge device for a wind turbine. Journal of Intelligent Material Systems and Structures, 23(6), 691-701. https://dx.doi.org/10.1177/1045389X12438622

Daynes, S., \& Weaver, P. M. (2012b). Design and testing of a deformable wind turbine blade control surface. 
Smart Materials and Structures, 21(10), 105019. https://dx.doi.org/10.1088/0964-1726/21/10/105019

Frøyd, L., \& Dahlhaug, O. G. (2011). Rotor design for a 10 MW offshore wind turbine. The Twenty-First International Offshore and Polar Engineering Conference. International Society of Offshore and Polar Engineers.

Fung, Y. C. (2002). An introduction to the theory of aeroelasticity. New York: Dover.

Gao, Z., \& Gao, R. (2016). Pitch control for wind turbine systems using optimization, estimation and compensation. Renewable Energy, 91, 501-515. https://dx.doi.org/10.1016/j.renene.2016.01.057

Hoogedoorn, E., Jacobs, G. B., \& Beyene, A. (2010). Aero-elastic behavior of a flexible blade for wind turbine $\begin{array}{lllll}\text { application: } \quad \text { a } 2 \mathrm{D} \text { computational study. Energy, } & 35(2), \quad 785 .\end{array}$ https://dx.doi.org/10.1016/j.energy.2009.08.030

Imraan, M., Sharma, R. N., \& Flay, R. G. J. (2013). Wind tunnel testing of a wind turbine with telescopic blades: The influence of blade extension. Energy, 53, 22-32. https://dx.doi.org/10.1016/j.energy.2013.03.008

Jonkman, J. M. (2009). Definition of a 5-MW reference wind turbine for offshore system development. Golden, Colo: National Renewable Energy Laboratory.

Pahasa, J., \& Ngamroo, I. (2016). Coordinated control of wind turbine blade pitch angle and PHEVs using MPCs for load frequency control of microgrid. IEEE Systems Journal, 10(1), 97-105. https://dx.doi.org/10.1109/JSYST.2014.2313810

Robinett, R. D., \& Wilson, D. G. (2010). Transient stability and control of renewable generators based on Hamiltonian surface shaping and power flow control: Part i-theory. In Control Applications (CCA), 2010 IEEE International Conference on (pp. 2196-2202). https://dx.doi.org/10.1109/CCA.2010.5611140

Singh, S. N., \& Yim, W. (2003). State feedback control of an aeroelastic system with structural nonlinearity. Aerospace Science and Technology, 7(1), 23-31. https://dx.doi.org/10.1016/S1270-9638(02)00004-4

Steel, W. (2015). Siemens looks toward next-generation 10-20 MW wind turbines. Retrieved from http://cleantechnica.com/2015/09/15/siemens-looks-toward-next-generation-10-20-mw-wind-turbines

Versailles, P., Ghosh, S., Vo, H. D., \& Masson, C. (2011). Preliminary assessment of wind turbine blade lift control via plasma actuation. Wind Engineering, 35(3), 339-356. https://dx.doi.org/10.1260/0309-524X.35.3.339

Wilson, D. G., Berg, D. E., Barone, M. F., Berg, J. C., Resor, B. R., \& Lobitz, D. W. (2009). Active aerodynamic blade control design for load reduction on large wind turbines. European Wind Energy Conference, Marseille, France, 26(19), 643-678.

Woods, B. K., Kothera, C. S., \& Wereley, N. M. (2011). Wind tunnel testing of a helicopter rotor trailing edge flap actuated via pneumatic artificial muscles. Journal of Intelligent Material Systems and Structures, 22(13), 1513-1528.

Woods, B. K., Kothera, C. S., \& Wereley, N. M. (2014). Whirl testing of a pneumatic artificial muscle actuation system for a full-scale active rotor. Journal of the American Helicopter Society, 59(2), 1-11. https://dx.doi.org/10.4050/JAHS.59.022006

Woods, B. K., Kothera, C. S., Sirohi, J., \& Wereley, N. M. (2011). Pneumatic artificial muscles for trailing edge flap actuation: a feasibility study. Smart Materials and Structures, 20(10), 105021. https://dx.doi.org/10.1088/0964-1726/20/10/105021

\section{Copyrights}

Copyright for this article is retained by the author(s), with first publication rights granted to the journal.

This is an open-access article distributed under the terms and conditions of the Creative Commons Attribution license (http://creativecommons.org/licenses/by/4.0/). 